\title{
İhracat Büyümenin İtici Gücü mü? Gelişmekte Olan Ülkelerden Kanitlar $^{1}$
}

\section{Sena TÜRKMEN}

Dr. Öğr. Üyesi, Niğde Ömer Halisdemir Üniversitesi, İktisadi ve İdari Bilimler Fakültesi, İktisat Bölümü senaturkmen@ohu.edu.tr

Orcid ID: https://orcid.org/ 0000-0002-8334-6466

\section{Sefa ÖZBEK}

Arş. Gör., Kahramanmaraş Sütçü İmam Üniversitesi, İktisadi ve İdari Bilimler Fakültesi, İktisat Bölümü sefaozbek@yahoo.com

Orcid ID: https://orcid.org/ 0000-0002-1043-2056

\section{Öz}

Dünya ekonomisinde serbest ticaret fikri uzun yıllardır tartışılmaktadır. Ülke ekonomilerinde çeşitli kırılmaların yaşandığ $1870-1914$ ilk küreselleşme dönemi, 1929 Büyük Bunalımı, 1970 Petrol Krizi, 1997 Asya Krizi ve son olarak 2008 Mortgage krizi gibi olaylar ülkeleri farklı ekonomik stratejilere itmiştir. 1960'lı y1llarda bazı ülkelerin serbest ticaret ile yüksek büyüme hızları elde etmesi ve 1980 sonrası yeni küreselleşme dönemi ile beraber ticaretin ve sermayenin önündeki kısıtlamaların en aza inmesiyle yüksek büyüme hedeflemeleri özellikle gelişmekte olan ülkelere cazip gelmiştir. Bu dönemde birçok ülkede ithal ikameci politikaların yerini ihracata dayalı büyüme politikaları almıştır.

$\mathrm{Bu}$ çalışmada seçilmiş 14 gelişmekte olan ülke için ihracata dayalı büyüme modeli 1967-2017 dönemi y1llık verileri ile dinamik panel veri metodu ile sınanmıştır. Panel nedensellik testlerinden olan Konya nedensellik testi kullanılarak yapılan analizde bulgular hem ihracattan ekonomiye büyümeye hem de ekonomik büyümeden ihracata doğru nedensellik ilişkisinin mevcut olmadığını göstermektedir.

Anahtar Kelimeler: İhracat, Ekonomik Büyüme, Dinamik Panel Veri.

\footnotetext{
${ }^{1}$ Makale Geliş/Kabul Tarihi: 27.04.2020 / 03.05.2021

Künye Bilgisi: Türkmen, S. ve Özbek, S. (2021). İhracat büyümenin itici gücü mü? Gelişmekte olan ülkelerden kanıtlar. Kahramanmaraş Sütçü Imam Üniversitesi Sosyal Bilimler Dergisi, 18(2), 1470-1484. DOI: 10.33437/ksusbd.728036.
} 


\title{
Is Export the Driving Force of Growth? Evidence from Developing Countries
}

\begin{abstract}
The idea of free trade in the world economy has been debated for many years. Events such as the first globalization period of 1870-1914, 1929 Great Depression, 1973 Oil Crisis, 1997 Asian Crisis and finally 2008 Mortgage Crisis, which caused various breakdowns in national economies, pushed countries to different economic strategies. It was especially attractive to developing countries that some countries achieved high growth rates with free trade in the 1960s and that the restrictions on trade and capital were minimized and new growth with the new globalization period after 1980s. In this period, import substitution policies were replaced by export-oriented growth policies in many countries.

In this study, the export-oriented growth model for the 14 developing countries selected has been tested by using the dynamic data method with the data of the period between 1967-2017. In the analysis made by using the Konya causality test, which is one of the panel causality tests, the findings show that there is no causality relationship from both export to economic growth and economic growth to export.
\end{abstract}

Keywords: Export, Economic Growth, Dynamic Panel Data.

\section{GíRIş̧}

İktisat yazınında 1945-1970 dönemi kapitalizmin altın çağı olarak bilinmektedir. 1970'li yıllarda OPEC ülkelerinin petrol fiyatlarını artırmalarından dolayı meydana gelen petrol krizi ile bu dönem sona ermiştir (Şahbaz, vd., 2014). Söz konusu dönemde özellikle Güney Kore, Singapur, Tayvan gibi ülkelerde ticaret serbestliğinin tetiklediği yüksek büyüme hıları, birçok gelişmekte olan ülke için ilham kaynağ 1 olmuştur ve ihracat artışı ile büyüme oranlarının yukarı seviyelere ulaşacağı beklentisi artmıştır (Kösekahyaoğlu ve Şentürk: 2006: 24). 1980'li yıllardan sonra, yeni küreselleşme dönemi olarak adlandırılan dönemde ticaretin önündeki kısıtların yanında sermayenin de serbest dolaşıma açılmasıyla birçok gelişmekte olan ülke ekonomisi etkilenmiştir. Yeni küreselleşme süreci ile birlikte birçok gelişmekte olan ülkede uygulanan ithal ikameci politika yerini ihracata dayalı büyüme stratejisine bırakmıştır. Temel anlamada bu hipotez, ihracatta meydana gelen artışın;

$\checkmark \quad$ Ülkeye döviz girişini 
$\checkmark \quad$ Yurtiçi yatırımları

$\checkmark$ Ölçek ekonomilerini

$\checkmark \quad$ Rekabeti ve verimliliği

$\checkmark$ İstihdam 1

$\checkmark \quad$ Teknoloji seviyesini

artırmak suretiyle ekonomik büyüme üzerinde olumlu etkiler bırakacağını ileri sürmektedir (Giles ve Williams, 2000:263). Dolayısıyla söz konusu dönemle birlikte birçok gelişmekte olan ülke için ihracata dayalı büyüme stratejisi, alternatif politika olarak uygulanmaya başlanmıştır.

İhracata dayalı büyüme stratejisini savunan iktisatçılar ve politikacılara göre ihracatta meydana gelen artış ülke ekonomisinin büyümesinin temel faktörüdür. Söz konusu hipotez 4 farklı nedenle ekonomik büyümenin itici gücüdür. Bunlar;

$\checkmark$ GSYIH'yı oluturan kalemlerden biri olan mal ve hizmet ihracatındaki artış, yurtiçi talebin azalmaması koşuluyla çarpan etkisi ile kamu harcamaları ve yatırım harcamalarında olduğu gibi üretim düzeyinde artmasına tetikleyerek üretim hacminin ve istihdamın genişlemesine yol açmaktadır (Ramos, 2001). Özellikle gelişmekte olan ülkelerde düşük gelir düzeyinden dolayı, tasarrufların az olduğu göz önüne alnırsa yatırımlar ve sermaye birikimlerinin düşük olduğu gözlenmektedir. Dolayısıyla söz konusu ülkeler, ihracat yoluyla, elde ettiği sermaye aracılığıyla üretim hacmini ve istihdamı artırarak büyüme oranlarını yukarı düzeylere çıkarabilmektedir.

$\checkmark \quad$ Gelişmekte olan ülkeler, üretim yapabilmek için fiziki sermaye mallarına ihtiyaç duyabilmektedir. Söz konusu ülkeler bu malları elde edebilmek için dövize ihtiyaç dutymaktadır. İhracat yoluyla döviz geliri elde eden ülkeler, gerekli mal ve hizme ithalatını artırarak üretim kapasitelerini, yatırımları artırma imkanı bulabilmektedirler. Dolayısıyla artan üretim kapasitesi ile birlikte üretim hacmi ve istihdam artmakta ve ülke ekonomisi büyümektedir (Sharma ve Panagiotidis, 2004; Şimşek, 2003; A ̆gayev, 2011).

$\checkmark \quad$ Ülkelerin ihracatlarını artırma yoluyla büyüyen üretim hacmi, ihractçı sektörlerde uzmanlaşmalara yol açmaktadır. Uzmanlaşmayla birlikte verimlilik artışı yaşanmakta ve ilgili sektörlerde kaynakların optimal biçimde kullanımı meydana gelmektedir (Shirazi ve Abdul Manap, 2005). Böylece, kaynaklar verimsiz sektörlerden verimli sektöllere kaymakta ve üretim hacmi genişlemektedir. 
$\checkmark \quad$ İhracat yapan bir ülke, diğer bir ifadeyle dış ticarete açılan bir ülke, D. Ricardo tarafından öne sürülen mukayeseli üstünlüklerden yararlanabilmektedir. Serbest diş ticaret ile ilgili sektörler rekabete gireceklerdir. Rekabet üstünlüğü elde etmek amacıyla bigi ve teknolojiyi önemseyecekler, araştırma geliştirme faaliyetleri yapacaklar, optimal kaynak dağılımının nasıl olması gerektiği konusunda projeler geliştireceklerdir (Ağayev, 2011). Dolayısıyla, ihracata açılan bir ülkede faalyet gösteren işletmeler, uluslararası rekabeti sürdürebilmek adına yapacakları bu girişimler ülke ekonomisinin büyümesine faydalı olacaktır.

Seçilmiş 14 gelişmekte olan ülke için ihracata dayalı büyüme stratejisinin geçerliliği, diğer bir deyişle ihracat ile büyüme arasında pozitif bir nedensellik ilişkisinin varlığı araştırılmaktadır. Çalışmanın devam eden bölümünde konuyla ilgili daha önce yapılmış olan çalışmalar özetlenecek, devamında ekonometrik bulgulara yer verilecektir. Son olarak sonuç ve öneriler ile çalışma sonlandirilacaktır.

\section{KONU İLE İLGILİ ÖNCEKİ ÇALIŞMALAR}

İktisat literatüründe, ihracata dayalı büyüme modeli ile ilgili çok sayıda araştırma bulunmaktadır. İhracatın ekonomik büyümenin nedeni olduğuna dayanan, görüşü destekleyen çalışmalar olduğu gibi ihracata dayalı büyüme modelinin geçersiz olduğu çalışmalarda mevcuttur. Dolayısıyla, araştırmalarda, görüş birliğine varılabilmiş değildir. Konu le ilgili literatürde yer alan bazı çalışmalar Tablo 1'de yer almaktadır.

Tablo 1. İhracat ve Ekonomik Büyüme İlişkisini Ele Alan Ampirik Çalışmalar

\begin{tabular}{|l|l|l|l|}
\hline Yazar & Ülke/Dönem & Yöntem & Sonuç \\
\hline Marin (1992) & $\begin{array}{l}\text { Birleşmiş Milletler, } \\
\text { Almanya, Japonya ve } \\
\text { İngiltere / } \\
1960-1987\end{array}$ & $\begin{array}{l}\text { Eş-bütünleşme ve } \\
\text { Granger } \\
\text { Nedensellik }\end{array}$ & $\begin{array}{l}\text { İhracata dayalı } \\
\text { büyüme hipotezi } \\
\text { geçerlidir. }\end{array}$ \\
\hline $\begin{array}{l}\text { Afxentiou ve } \\
\text { Serletis (2000) }\end{array}$ & 50 ülke / 1970-1993 & $\begin{array}{l}\text { Granger } \\
\text { Nedensellik Testi }\end{array}$ & $\begin{array}{l}\text { İhracata dayalı } \\
\text { büyüme hipotezi } \\
\text { geçerli değildir. }\end{array}$ \\
\hline Kónya (2006) & $\begin{array}{l}\text { 25 OECD Ülkesi/ } \\
1960-1998\end{array}$ & $\begin{array}{l}\text { İhracat ve } \\
\text { büyüme } \\
\text { arasinda seçilen } \\
\text { ülkelerde } \\
\text { çoğunlukla tek } \\
\text { yönlü ilişki } \\
\text { Analizi } \\
\text { olmakla birlikte } \\
\text { az sayıda ülke } \\
\text { için çift yönlü } \\
\text { ilişki mevcuttur. }\end{array}$ \\
\hline
\end{tabular}




\begin{tabular}{|c|c|c|c|}
\hline Agosin (2009) & $\begin{array}{l}\text { Yükselen Piyasa } \\
\text { Ekonomileri/ } \\
\text { 1980-2003 }\end{array}$ & $\begin{array}{l}\text { Panel Regresyon } \\
\text { Veri Analizi }\end{array}$ & $\begin{array}{l}\text { İhracatın } \\
\text { teknoloji yoğun } \\
\text { olarak yapılması } \\
\text { ekonomik } \\
\text { büyümeyi } \\
\text { pozitif yönde } \\
\text { etkilemektedir. }\end{array}$ \\
\hline $\begin{array}{l}\text { Çetintaş ve } \\
\text { Barışık (2009) }\end{array}$ & $\begin{array}{l}13 \text { Geçiş ekonomisi/ } \\
1995-2006\end{array}$ & $\begin{array}{l}\text { Granger } \\
\text { Nedensellik Testi }\end{array}$ & $\begin{array}{l}\text { Ekonomik } \\
\text { büyümeden } \\
\text { ihracata doğru } \\
\text { tek yönlü bir } \\
\text { nedensellik } \\
\text { vardır. }\end{array}$ \\
\hline Nasreen (2011) & $\begin{array}{l}\text { Gelişmekte olan } 8 \\
\text { Asya ülkesi// } \\
1975-2008\end{array}$ & $\begin{array}{l}\text { Panel Regresyon } \\
\text { Veri Analizi }\end{array}$ & $\begin{array}{l}\text { Ekonomik } \\
\text { büyümeden } \\
\text { ihracata doğru } \\
\text { ilişki vardır. }\end{array}$ \\
\hline Ağayev (2011) & $\begin{array}{l}12 \text { Geçiş Ekonomisi/ } \\
\text { 1994-2008 }\end{array}$ & $\begin{array}{l}\text { Panel } \\
\text { Eşbütünleşme ve } \\
\text { Panel Nedensellik } \\
\text { Analizi } \\
\end{array}$ & $\begin{array}{l}\text { İhracata dayalı } \\
\text { büyüme hipotezi } \\
\text { geçerlidir. }\end{array}$ \\
\hline $\begin{array}{l}\text { Dreger ve } \\
\text { Herzer (2013) }\end{array}$ & $\begin{array}{l}\text { Gelişmekte olan } 45 \\
\text { ülke / 1971-2005 }\end{array}$ & $\begin{array}{l}\text { Panel Eş- } \\
\text { bütünleşme Testi }\end{array}$ & $\begin{array}{l}\text { Kisa dönemde } \\
\text { ihracat ve } \\
\text { büyüme } \\
\text { arasında çift } \\
\text { yönlü } \\
\text { nedensellik } \\
\text { mevcuttur. } \\
\text { Uzun dönemde } \\
\text { etki mevcut } \\
\text { değildir. }\end{array}$ \\
\hline $\begin{array}{l}\text { Aditya ve } \\
\text { Acharya (2013) }\end{array}$ & $\begin{array}{l}65 \text { Seçilmiş ülke/ } \\
1965-2005\end{array}$ & $\begin{array}{l}\text { Dinamik Panel } \\
\text { Veri Analizi }\end{array}$ & $\begin{array}{l}\text { İhracat artışı } \\
\text { ekonomik } \\
\text { büyümeyi } \\
\text { artırmaktadır. }\end{array}$ \\
\hline $\begin{array}{l}\text { Yardımcıoğlu ve } \\
\text { Gülmez (2013) }\end{array}$ & $\begin{array}{l}6 \text { Seçilmiş ülke/ } \\
1995-2011\end{array}$ & $\begin{array}{l}\text { Panel Granger } \\
\text { Nedensellik Testi, } \\
\text { Panel Eş- } \\
\text { bütünleşme Testi }\end{array}$ & $\begin{array}{l}\text { Uzun dönemde } \\
\text { ihracat ve } \\
\text { büyüme } \\
\text { arasında pozitif } \\
\text { bir ilişki } \\
\text { mevcuttur. }\end{array}$ \\
\hline $\begin{array}{l}\text { Şahbaz vd., } \\
(2014)\end{array}$ & $\begin{array}{l}27 \text { Seçilmiş Asya } \\
\text { ülkesi/ 1994-2010 }\end{array}$ & $\begin{array}{l}\text { Panel Eş- } \\
\text { bütünleşme } \\
\text { Testi, } \\
\text { Panel nedensellik } \\
\text { Testi }\end{array}$ & $\begin{array}{l}\text { Uzun ve kısa } \\
\text { dönemde } \\
\text { ihracata dayalı } \\
\text { büyüme hipotezi } \\
\text { geçerlidir. }\end{array}$ \\
\hline
\end{tabular}




\begin{tabular}{|c|c|c|c|}
\hline Keho (2015) & $\begin{array}{l}12 \text { Afrika ülkesi/ } \\
1970-2013\end{array}$ & $\begin{array}{l}\text { Johansen Eş- } \\
\text { bütünleşme Testi, } \\
\text { Granger } \\
\text { Nedensellik Testi }\end{array}$ & $\begin{array}{l}\text { Sonuçlar } \\
\text { ülkelere göre } \\
\text { farklılık } \\
\text { göstermiştir. } \\
\text { Bazı ülkelerde } \\
\text { karşıllıkı } \\
\text { nedensellik } \\
\text { ilişkisi } \\
\text { mevcuttur. } \\
\end{array}$ \\
\hline $\begin{array}{l}\text { Değer ve } \\
\text { Doğanay (2016) }\end{array}$ & $\begin{array}{l}21 \text { Yükselen Piyasa } \\
\text { Ekonomisi/ 1996- } \\
2014\end{array}$ & $\begin{array}{l}\text { ECM, Panel Eş- } \\
\text { bütünleşme } \\
\text { Testi }\end{array}$ & $\begin{array}{l}\text { Uzun dönemde } \\
\text { yükselen piyasa } \\
\text { ekonomilerinde } \\
\text { büyümenin } \\
\text { ihracata olumlu } \\
\text { yönde etkisi } \\
\text { vardır. }\end{array}$ \\
\hline $\begin{array}{l}\text { Yüksel ve } \\
\text { Zengin (2016) }\end{array}$ & $\begin{array}{l}\text { Arjantin, Brezilya, } \\
\text { Çin, Malezya, } \\
\text { Meksika ve Türkiye/ } \\
\text { 1961-2014 }\end{array}$ & $\begin{array}{l}\text { Engle Granger } \\
\text { Eşbütünleşme } \\
\text { Analizi, VECM } \\
\text { ve Toda } \\
\text { Yamamoto } \\
\text { Nedensellik } \\
\text { Analizi }\end{array}$ & $\begin{array}{l}\text { Sadece } \\
\text { Arjantin'de } \\
\text { ihracata dayalı } \\
\text { büyüme hipotezi } \\
\text { geçerlidir. }\end{array}$ \\
\hline Ersin (2018) & $\begin{array}{l}\text { Meksika, Endonezya, } \\
\text { Nijerya, Türkiye/ } \\
\text { 1960-2016 }\end{array}$ & $\begin{array}{l}\text { Toda Yamamoto } \\
\text { Nedensellik } \\
\text { Analizi }\end{array}$ & $\begin{array}{l}\text { Türkiye ve } \\
\text { Meksika'da } \\
\text { ihracata dayalı } \\
\text { büyüme hipotezi } \\
\text { geçerli. }\end{array}$ \\
\hline
\end{tabular}

\section{AMPÍRIK ANALIZ}

Gelişmekte olan ülkeler kapsamında ihracat ve büyüme arasındaki ilişkiyi inceleyen bu çalışmada dinamik panel veri analizi kullanılmıştır. Çalışmada verilerine tam olarak ulaşılabilen 14 gelişmekte olan ülke için 1967-2017 dönemi dikkate alınmıştır.

İhracat ve büyüme arasındaki ilişkinin test edildiği çalışmada üç değişken kullanılmaktadır. Çalışmada kullanılan değişkenler Dünya Bankası 'World Development Indicators' veri tabanından alınmış ve kullanılan değişkenler, Tablo 2'de tanımlanmıştır. 
Tablo 2. Değişkenlerin Tanımlanması

\begin{tabular}{|c|c|c|}
\hline Değişkenler & Açıklama & Kaynak \\
\hline LGDP & $\begin{array}{l}\text { Logaritmik Kişi Başına Düşen } \\
\text { Gelir (ABD \$) }\end{array}$ & $\begin{array}{c}\text { Dünya Bankası, World } \\
\text { Development Indicators, } \\
\text { 1967-2017 }\end{array}$ \\
\hline LEX & $\begin{array}{lccr}\text { Logaritmik } & \text { Mal } & \text { ve } & \text { Hizmet } \\
\text { İhracatının } & \text { GSYİH } & \text { İçerisindeki } \\
\text { Payı (\%) } & & \end{array}$ & $\begin{array}{c}\text { Dünya Bankası, World } \\
\text { Development Indicators, } \\
\text { 1967-2017 }\end{array}$ \\
\hline
\end{tabular}

Tablo 1' de gösterilen ve logaritmik dönüşümleri yapılan değişkenlerle oluşturulan model Denklem 1' deki gibidir. Modellerde i; kesit boyutunu ve t; zaman boyutunu göstermektedir.

$$
\begin{aligned}
& L G D P_{i t}=\alpha_{i}+\beta_{1 i} L E X_{i t}+\varepsilon_{i t} \\
& (i=1, \ldots 14) \text { ve }(t=1967, \ldots, 2017)
\end{aligned}
$$

Tablo 3. Modelde Yer Alan Ülkeler

\begin{tabular}{|c|l|c|l|}
\hline Sira & Ülke & Sıra & Ülke \\
\hline 1 & Arjantin & 8 & Peru \\
\hline 2 & Brezilya & 9 & Güney Afrika \\
\hline 3 & Çin & 10 & Türkiye \\
\hline 4 & Endonezya & 11 & Pakistan \\
\hline 5 & Meksika & 12 & Kolombiya \\
\hline 6 & Malezya & 13 & Şili \\
\hline 7 & Filipinler & 14 & Hindistan \\
\hline
\end{tabular}

Tablo 3'te model de yer alan seçilmiş 14 yükselen piyasa ekonomisine yer verilmiştir. Denklem (1)'i tahmin edebilmek için ön testler olan homojenite ( $\Delta$ testi) ve yatay kesit bağımlılı̆̆ $\left(\mathrm{CD}_{\mathrm{LM}}\right)$ testleri yapılmaktadır. İhracat ve ekonomik büyüme arasındaki nedensellik ilişkisinin yönü Konya (2006) panel nedensellik testi ile incelenmektedir.

\section{Yöntem}

$\mathrm{Bu}$ çalışmada, yeni ekonometrik yöntemlerle dinamik panel veri analizi kullanılmıştır. Panel veri analizinde ele alınan incelemeler, yatay kesit 
birimlerine zaman boyutunun eklenmesiyle grup ve zaman etkilerini görebilmeye olanak sağlamaktadır.

İhracat ve ekonomik büyüme arasındaki nedensel ilişkiyi tahmin edebilmek için bazı ön testlere ihtiyaç duyulmaktadır. Bu ön testlerden biri, kesitler arasında bağımlılık olup olmadığının araştırılmasıdır. Günümüzde artan dış ticaret, finansal serbestleşme ve küreselleşme hareketlerinin etkisiyle birlikte, bir ülke ekonomisinde ortaya çıkan bir şokun diğer ülkeleri etkilemesi kaçınılmazdır. Bu durum, ampirik analizlerde yatay kesit bağımlılık "cross-section dependency" testleri ile belirlenebilmektedir. Değişkenlerde ve modelde kesitler arası bağımlılık olup olmadığına karar vermek için Breusch ve Pagan (1980) LM (Lagrange Multiplier) testi, CD (Cross Section Dependency) testi ve $\mathrm{CD}_{\mathrm{LM}}$ testi (Pesaran (2004)) ile Pesaran vd. (2008) tarafindan geliştirilen LMadj (BiasAdjusted Cross Sectionally Dependence Lagrange Multiplier) testlerinden yararlanılmaktadır. Testin sıfır hipotezi " $\mathrm{H}_{0}$ : Kesitler arası bağımlılık yoktur" varsayımı üzerine kuruludur. Ampirik bulgulara göre, sıfır hipotezinin reddedilememesi, ülkeler arasında yatay kesit bağımlılığının olmadığını yani bir ülkede ortaya çıkan makroekonomik bir şokun paneli oluşturan diğer ülkeleri etkilemediğini göstermektedir (Baltagi, 2008:284). Analizlerde yatay kesit bağımlılığının tespit edilmesi durumunda, bu sonucun göz önünde bulundurulması elde edilen analiz sonuçlarını önemli ölçüde etkilemektedir (Breusch ve Pagan, 1980).

Yapılması gereken ön testlerden biri, değişken katsayılarının homojen mi yoksa heterojen mi olduğunun araştırılmasıdır. Değişken katsayılarının heterojen olduğu tespit edilirse, heterojeniteyi dikkate alan birim kök analizlerinin yapılması gerekmektedir. Katsayı homojenliği, Pesaran ve Yamagata (2008) tarafından geliştirilen Eğim Homojenliği Testi (Slope Homogeneity Test- $\Delta$ testi) ile incelenmektedir. Delta testi, büyük örneklemler için; Delta adj testi, küçük örneklemler için geçerlidir. Homojenite testinde sıfır hipotezi " $\mathrm{H}_{0}$ : Katsayılar homojendir" ve alternatif hipotez " $\mathrm{H}_{1}$ : Katsayllar heterojendir" şeklindedir. Homojenite testi, kesitlerden birinde gerçekleşen değişim ile diğer kesitlerin aynı düzeyde etkilenip etkilenmediğini ortaya koymaktadır.

$\mathrm{Bu}$ analizler sonucunda birim kök ve eş bütünleşme testlerinin yapılması zorunluluğu olmadan değişkenlerin düzey değerleri ile Konya (2006) panel nedensellik testi yapılarak değişkenler arasındaki nedensel ilişkinin yönü belirlenmektedir (Konya, 2006: 982). Zellner (1962) tarafindan oluşturulan görünürde ilişkisiz regresyon (GİR) tahmincilerine dayanan, Kónya (2006) panel nedensellik testinde, diğer panel nedensellik testlerinden farklı olarak her bir yatay kesit birimi için hesaplanan bootstraplı kritik değerler kullanılmaktadır. Konya'nın nedensellik analizindeki bir başka farklılık ise durağan olmayan veya eşbütünleşik olmayan seriler ile testin yapılabilmesidir. Böylece birim kök ve 
eşbütünleşme analizleri yapılmaksızın serilerin düzey değerleri ile analiz yapılabilmektedir (Kónya, 2006). Yatay kesit bağımlılığının olması durumunda, panel veri analizlerinde GIR tahmincileri, EKK tahmincilerine göre daha etkin sonuçlar ortaya koymaktadır. Bundan dolayı Kónya panel nedensellik testinin tercih edilmesi daha güvenilir sonuçlar vermektedir. Kónya panel nedensellik testi için kullanılacak denklem sistemi şu şekildedir (Kónya, 2006).

$$
\begin{aligned}
& Y_{1, t}=a_{1,1}+\sum_{i=1}^{l y_{1}} \beta_{1,1, i} Y_{1, t-i}+\sum_{i=1}^{l x_{1}} \delta_{1,1, i} X_{1, t-i}+\varepsilon_{1,1, t} \\
& Y_{2, t}=a_{1,2}+\sum_{i=1}^{l y_{1}} \beta_{1,2, i} Y_{2, t-i}+\sum_{i=1}^{l x_{1}} \delta_{1,2, i} X_{2, t-i}+\varepsilon_{1,2, t} \\
& \text {. } \\
& Y_{N, t}=a_{1, N}+\sum_{i=1}^{l y_{1}} \beta_{1, N, i} Y_{N, t-i}+\sum_{i=1}^{l x_{1}} \delta_{1, N, i} X_{N, t-i}+\varepsilon_{1, N, t} \\
& X_{1, t}=a_{2,1}+\sum_{i=1}^{l y_{2}} \beta_{2,1, i} Y_{1, t-i}+\sum_{i=1}^{l x_{2}} \delta_{2,1, i} X_{1, t-i}+\varepsilon_{2,1, t} \\
& X_{2, t}=a_{2,2}+\sum_{i=1}^{l y_{2}} \beta_{2,2, i} Y_{2, t-i}+\sum_{i=1}^{l x_{2}} \delta_{2,2, i} X_{2, t-i}+\varepsilon_{2,2, t} \\
& X_{N, t}=a_{2, N}+\sum_{i=1}^{l y_{2}} \beta_{2, N, i} Y_{N, t-i}+\sum_{i=1}^{l x_{2}} \delta_{2, N, i} X_{N, t-i}+\varepsilon_{2, N, t}
\end{aligned}
$$

Denklemler sistemindeki $l$ Akaike ve Schwarz bilgi kriterleri yardımıyla belirlenen uygun gecikme uzunluğunu ve $N$ yatay kesit birim sayısın $1(\mathrm{j}=1, . ., N)$ $\mathrm{j}, t$ ise zaman boyutunu ( $t=1, . ., \mathrm{T}$ ) ifade etmektedir. (Kónya, 2006: 982-983). Kónya testi için Wald test istatistiği hesaplanmaktadır. Bu sistemde $\delta_{1, j, i}$ değiş̧keni tüm birimler için sıfira eşit değil iken $\beta_{2, j, i}$ değişkeni tüm birimler için sıfıra eşit ise $X$ 'ten $Y$ 'ye doğru tek yönlü bir Granger nedensellik söz konusudur. 
$\delta_{1, j, i}$ ve $\beta_{2, j, i}$ değişkenlerinin her ikisi de sıfıra eşit değil ise $X$ ile $Y$ arasında çift yönlü bir nedensellik söz konusu iken

$\delta_{1, j, i}, \beta_{2, j, i}$ değişkenlerinin her ikisi de sıfıra eşit ise $X$ ile $Y$ arasında bir nedensellik ilişkisi söz konusu değildir.

\section{Bulgular}

Panel nedensellik testlerinden hangisinin yapılacağına karar vermeden önce değişken katsayısının homojen mi yoksa heterojen mi olup olmadığına ve kesitler arası bağımlılık olup olmadığ 1 test edilmelidir. Tablo 4 'te homojenite ve yatay kesit bağımlılı̆̆

Tablo 4. Homojenite ve Yatay Kesit Bağımlılığı Test Sonuçları

\begin{tabular}{|c|c|c|c|c|}
\hline \multicolumn{5}{|c|}{ Homojenite Test Sonuçları } \\
\hline Testler & \multicolumn{2}{|c|}{ Test İstatistiği } & \multicolumn{2}{|c|}{ Olasılık Değeri } \\
\hline Delta Tilde & & $1.311^{*}$ & & 0.095 \\
\hline Delta Tilde $_{a j j}$ & & $1.352^{*}$ & & 0.088 \\
\hline \multicolumn{5}{|c|}{ Yatay Kesit Bağımlılığı Test Sonuçları } \\
\hline Değişkenler & \multicolumn{2}{|c|}{ LGDP } & \multicolumn{2}{|c|}{ LEX } \\
\hline Testler & $\begin{array}{l}\text { İst. } \\
\text { Değeri }\end{array}$ & $\begin{array}{l}\text { Olasılık } \\
\text { Değeri }\end{array}$ & $\begin{array}{l}\text { İst. } \\
\text { Değeri }\end{array}$ & $\begin{array}{l}\text { Olasılık } \\
\text { Değeri }\end{array}$ \\
\hline $\mathrm{CD}_{\operatorname{lm} 1}(\mathrm{BP}, 1980)$ & $\begin{array}{r}112.753 \\
*\end{array}$ & 0.061 & $\begin{array}{r}152.135 \\
* * *\end{array}$ & 0.000 \\
\hline $\begin{array}{l}\mathrm{CD}_{\operatorname{lm} 2} \text { (Pesaran, } \\
2004)\end{array}$ & $1.612^{*}$ & 0.053 & $4.532^{* * *}$ & 0.000 \\
\hline $\begin{array}{l}\mathrm{CD}_{\operatorname{lm} 3} \text { (Pesaran, } \\
2004)\end{array}$ & $4.096^{* * *}$ & 0.000 & $4.208^{* * *}$ & 0.000 \\
\hline $\begin{array}{l}\mathrm{LM}_{\mathrm{adj}} \\
2008)\end{array}$ & 143.156 & 0.000 & $77.433^{* *}$ & 0.000 \\
\hline
\end{tabular}

Not: “***” işareti \%1 ve “*” işareti \%10 seviyesinde anlamlılı̆̆ model kullanılmıştır.

Tablo 3’te yer alan sonuçlara göre katsayının homojen olduğu üzerine kurulu sıfır hipotezi \%10 anlamlılık düzeyinde reddedilmekte olup, katsayının heterojen olduğu bulgusu elde edilmiştir. Bu durum, ihracat üzerinde meydana gelen bir değişimin ekonomik büyüme üzerindeki etkisinin her ülkede farklı sonuçlara yol açtığını ortaya koymaktadır. Aynı tabloda yer alan yatay kesit bağımlılığı test sonuçlarına göre kesitler arası bağımlılığının yokluğunu sınayan sıfır hipotezi \%1 ve $\% 10$ anlamlılık düzeylerinde reddedilmektedir. Elde edilen bulgular, kesitlerden birinde ortaya çıkan makroekonomik bir şokun diğer kesitleri de etkilediğini ortaya koymaktadır. 
Tablo 5'te yatay kesit bağımlılığını dikkate alan Konya (2006) panel nedensellik test sonuçları yer almaktadır.

Tablo 5. Panel Nedensellik Test Sonuçları, Konya (2006)

\begin{tabular}{|c|c|c|c|c|}
\hline \multirow[b]{2}{*}{ Ülke Sonuçları } & \multicolumn{2}{|c|}{ LGDP $\rightarrow$ LEX } & \multicolumn{2}{|c|}{ LEX $\rightarrow$ LGDP } \\
\hline & $\begin{array}{c}\text { Wald } \\
\text { İstatistiği }\end{array}$ & $\begin{array}{l}\text { Olasılık } \\
\text { Değeri }\end{array}$ & $\begin{array}{c}\text { Wald } \\
\text { İstatistiği }\end{array}$ & $\begin{array}{l}\text { Olasılık } \\
\text { Değeri }\end{array}$ \\
\hline Arjantin & 0.384 & 0.360 & $4.256^{* *}$ & 0.020 \\
\hline Brezilya & 2.589 & 0.240 & $10.046^{* * *}$ & 0.000 \\
\hline Çin & 0.106 & 0.950 & $8.102^{* *}$ & 0.010 \\
\hline Endonezya & 0.057 & 0.790 & 0.599 & 0.790 \\
\hline Meksika & 7.962 & 0.110 & $16.470^{* * *}$ & 0.000 \\
\hline Malezya & 0.178 & 0.630 & 0.335 & 0.260 \\
\hline Filipinler & 0.570 & 0.780 & 2.037 & 0.210 \\
\hline Peru & 1.895 & 0.220 & $2.200^{* *}$ & 0.030 \\
\hline Güney Afrika & 0.719 & 0.450 & $9.279^{* * *}$ & 0.000 \\
\hline Türkiye & 5.681 & 0.190 & $11.765^{* * *}$ & 0.000 \\
\hline Pakistan & 0.206 & 0.500 & 0.030 & 0.970 \\
\hline Kolombiya & 0.536 & 0.850 & $19.408^{* * *}$ & 0.000 \\
\hline Şili & 3.650 & 0.160 & $7.624^{* * *}$ & 0.000 \\
\hline Hindistan & 0.015 & 0.980 & $7.055^{* *}$ & 0.040 \\
\hline Fisher & 25.243 & 0.615 & 20.213 & 0.857 \\
\hline
\end{tabular}

Tablo 5'te yer alan panel nedensellik sonuçlarına göre "İhracat ekonomik büyümenin nedeni değildir" ve "Ekonomik büyüme ihracatın nedeni değildir" üzerine kurulu sıfir hipotezleri reddedilememektedir. Elde edilen bulgulara göre, 14 gelişmekte olan ülkenin panel sonuçlarında ihracattan ekonomik büyümeye ve ekonomik büyümeden ihracata doğru nedensellik ilişkisine rastlanmamıştır. Bulgular ülke bazında incelendiğinde; Arjantin, Brezilya, Çin, Meksika, Peru, Güney Afrika, Türkiye, Kolombiya, Şili ve Hindistan için ihracattan ekonomik büyümeye doğru tek yönlü nedensellik ilişkisinin varlığı tespit edilmiştir. Ancak seçilmiş ülkelerin hiçbirinde ekonomik büyümeden ihracata doğru bir nedensellik ilişkisi olduğu bulgusuna rastlanmamıştır.

\section{SONUÇ VE ÖNERILER}

Bu çalışmada, 1967-2017 dönemi için gelişmekte olan 14 ülkede ihracat artışının çıktı artışını destekleyerek ekonomik büyümeyi sağlayıp sağlamadığ panel nedensellik testi yardımıyla sınanmıştır. Elde edilen bulgular, söz konusu ülke grubunda ihracattan ekonomik büyümeye ve ekonomik büyümeden ihracata doğru bir nedensellik ilişkisi olmadığını ortaya koymuştur. Paneli oluşturan 
ülkeler bireysel olarak incelendiğinde ise Arjantin, Brezilya, Çin, Meksika, Peru, Güney Afrika, Türkiye, Kolombiya, Şili ve Hindistan'da ihracattan ekonomik büyümeye doğru tek yönlü nedensellik ilişkisi olduğu sonucu elde edilmiştir. Analiz için seçilen ülkelerin büyüme hızları, dış ticaret potansiyelleri ve izledikleri ekonomi politikaları birbirinden farklı olduğundan panel sonucu olarak nedensellik ilişkisi bulunamamış ve ülkelerin benzer şekilde hareket etmediği sonucuna ulaşılmıştır. Ancak ihracattan ekonomik büyümeye doğru nedensellik ilişkisine rastlanan 10 ülkede ihracata dayalı büyüme hipotezinin desteklendiği bulgusu elde edilmiştir. Elde edilen sonuçlara paralel olarak başta Çin ve Hindistan olmak üzere Türkiye ve Brezilya gibi ülkelerin çeşitli üretim alanlarında küresel birer aktör haline geldiği anlaşılmaktadır. Dolayısıyla ihracat, ekonomik büyüme stratejisinin önemli bir ayağını oluşturmakta ve ülkelerin büyümesi ve kalkınması bakımından önem arz etmektedir. Paneli oluşturan ülkelerin çoğunlukla dış ticaret açığ 1 verdiği göz önüne alındığında, bu açığı en aza indirmeye yönelik politikaların, söz konusu ülkelerde istikrarlı bir ekonomik büyüme sağlayacağı düşülmektedir. Ayrıca, ilgili ülkelerin mevcut potansiyelleri düşünüldüğünde araştırma-geliştirme faaliyetlerine ve teknolojik yatırımlara daha fazla yatırım yapmaları halinde, daha verimli üretim gerçekleştirebilecekleri ve daha yüksek büyüme ve kalkınma hızlarına erişebilecekleri düşünülmektedir. Söz konusu ülkelerde, politika yapıcıların, ihracatı özendirici teşvikler vb. hamlelerde bulunması da, gelişmekte olan ülkelerin bir üst gelişmişlik düzeyine çıkmaları adına önemli bir adım olarak görülmektedir.

\section{KAYNAKÇA}

Aditya, A. and Acharrya, R. (2013). Export diversification, composition, and economic growth: Evidence from Cross country analysis, The Journal of International Trade \& Economic Development, 22 (7), 959-992.

Afxentiou, P. and Serletis, A. (2000). Output growth and variability of export and import growth: International evidence from granger causality tests, The Developing Economies, 38(2), 141-163.

Agosin, M. (2009) Export diversification and growth in emerging economies, Economics, School of Economics and Business, University of Chile, 115131.

Ağayev, S. (2011). İhracat ve ekonomik büyüme ilişkisi: 12 geçiş ekonomisi örneğinde panel eşbütünleşme ve panel nedensellik analizleri, Ege Akademik Bakış, 11(2), 241-254.

Baltagi, B. (2008). Econometric analysis of panel data, John Wiley \& Sons. 
Breusch, T. S., and Adrian R. P. (1980).The Lagrange multiplier test and its applications to model specification in econometric, The Review Of Economic Studies 47(1): 239-253.

Çetintaş, H. and Barışık, S. (2008), Export, import and economic growth: The case of transition economies, Transition Studies Review, 15, 636-649.

Değer, K. M. ve Doğanay, A. M. (2016). Yükselen piyasa ekonomilerinde ihracat ve ekonomik büyüme: panel veri analizi (1996-2014), Paradoks Ekonomi, Sosyoloji ve Politika Dergisi, 12 (2), 52-71.

Dilber, İ. ve Sönmez Erataş, F. (2016). Thirlwall kanununun gelişmiş ülkeler açısından geçerliliği: Panel veri analizi, Uluslararası Alanya Işsetme Fakültesi Dergisi, 8 (2), 139-150.

Dreger, C. and Herzer, D. (2013). A further examination of the export-led growth hypothesis, FIW Working Paper, 84, 1-33.

Ersin, İ.. (2018). İhracata dayalı büyüme hipotezinin test edilmesi: MINT ülkeleri örneği, Ekonomi Işsletme ve Maliye Araştırmaları Dergisi, 1(1), 26-38.

Giles, J.A. ve Williams C. L. (2000). Export-led growth: a survey of the empirical literature and some non-causality results part 1 , The Journal of International Trade \& Economic Development, 9(3), 261-337.

Kar, M., Ağır, H. ve Türkmen, S. (2018). Gelişmekte olan ülkelerde elektrik tüketimi ile ekonomik büyüme ilişkisinin ekonometrik tahmini, International Congress on Political, Economic and Social Studies (ICPESS), ss.1-16.

Keho, Y. (2015), Foreign direct investment, exports and economic growth: Some African evidence, Journal of Applied Economics and Business Research, 5 (4), 209-219.

Kónya, L. (2006). Exports and growth: Granger causality analysis on OECD countries with a panel data approach, Economic Modelling, 23, 978-992.

Kösekahyaoğlu, L .ve Şentürk, C. (2006). İhracata dayalı büyüme hipotezinin testi: türkiye ve yeni gelişen ekonomilerin üzerine karşılaş̧ırmalı bir inceleme, Süleyman Demirel Üniversitesi Sosyal Bilimler Enstitüsü Dergisi, (4), 23-45.

Marin, D. (1992). Is the export-led growth hypothesis valid for industrialized countries? The Review of Economics and Statistics, 678-688. 
Nasreen, S. (2011). Export-Growth linkages in selected Asian developing countries: evidence from panel data analysis, Asian Journal of Empirical Research, 1 (1), 1-13.

Pesaran, M. H, Aman U., and Takashi Y. (2008). A bias-adjusted LM test of error cross-section independence, The Econometrics Journal 11.1: 105-127.

Pesaran, M. H., and Takashi Y. (2008), Testing slope homogeneity in large panels, Journal of econometrics 142(1), 50-93.

Pesaran, M. H.. (2004), General diagnostic tests for cross section dependence in panels, CESifo Working Paper 1229; IZA Discussion Paper 1240.

Ramos, F. F. R. (2001). Exports, 1mports, and economic growth in Portugal: evidence from causality and cointegration analysis, Economic Modelling, 18, 613-623.

Sharma, A. ve Panagiotidis, T. (2004). An analysis of exports and growth in india: cointegration and causality evidence (1971-2001), Sheffield Economic Research Paper Series SERP No: 2003004.

Shirazi, Nasim S., and Turkhan A. Abdul M. (2005). Export-led growth hypothesis: further econometric evidence from South Asia, The Developing Economies, 43(4), 472-88.

Şahbaz, A., Ağır, H. ve Yanar, R. (2014). Seçilmiş Asya ülkeleri için ihracata dayalı büyüme modeli: panel eşbütünleşme ve nedensellik analizi, Yönetim ve Ekonomi Araştırmaları Dergisi, 22, 24-43.

Şimşek, M. (2003). İhracata dayalı büyüme hipotezinin Türkiye ekonomisi verileri ile analizi, 1960-2002, D.E.Ü. İ.I.B.F. Dergisi, 18(2), 43-63.

Waithe, Kimberly, Lorde, Troy ve Francis, Brian (2011). Export-led growth: A case study of Mexico, International Journal of Business, Humanities and Technology, 1 (1), 33-44.

Yardımcıoğlu, F. ve Gülmez, A. (2013). Türk Cumhuriyetlerinde ihracat ve ekonomik büyüme ilişkisi: Panel eşbütünleşme ve panel nedensellik analizi, Bilgi Ekonomisi ve Yönetimi Dergisi, 8 (1), ss. 146-161.

Yüksel, S. ve Zengin, S. (2016). Causality relationship between import, export and growth rate in developing countries, International Journal of Commerce and Finance, 2(1), 147-156. 
Zellner, A. (1962). An efficient method of estimating seemingly unrelated regressions and tests for aggregation bias, Journal of the American statistical Association, 57(298), 348-368. 